\title{
Correction to: The Archaeological Record of Lagoa Santa (East-Central Brazil): From the Late Pleistocene to Historical Times
}

André Strauss, Igor M. Mariano Rodrigues, Alenice Baeta, Ximena S. Villagran, Marcony Alves, Francisco Pugliese Jr., Marcos Bissaro Jr., Rodrigo Elias de Oliveira, Gustavo Neves de Souza, Lucas Bueno, João Carlos Moreno de Sousa, Johnica J. Morrow, Karl J. Reinhard, Tiago Hermenegildo, Glauco Constantino Perez, Eliane Nunes Chim, Rafael de Oliveira dos Santos, Maurício de Paiva, Renato Kipnis, and Walter Neves

\section{Correction to: \\ Chapter "The Archaeological Record of Lagoa Santa (East-Central Brazil): From the Late Pleistocene to Historical Times" in: A. S. Auler and P. Pessoa (eds.), Lagoa Santa Karst: Brazil's Iconic Karst Region, Cave and Karst Systems of the World, https://doi.org/10.1007/978-3-030-35940-9_12}

The original version of the chapter "The Archaeological Record of Lagoa Santa (East-Central Brazil): From the Late Pleistocene to Historical Times" was inadvertently published with errors in the author names, which were incorrectly listed as João Carlos Moreno de Souza and Glauco Constantino instead of João Carlos Moreno de Sousa and Glauco Constantino Perez, respectively. Further, on page 267, the incorrect name "Ferreira" was replaced with the correct name "Ferraz" in the caption for Fig. 21.

The chapter and book have been updated with the changes.

The updated version of this chapter can be found at https://doi.org/10.1007/978-3-030-35940-9_12 